\title{
Predictors of surgical outcomes after in situ ulnar nerve decompression for cubital tunnel syndrome
}

This article was published in the following Dove Press journal:

Therapeutics and Clinical Risk Management

\section{Lingde Kong* \\ Jiangbo Bai* \\ Kunlun Yu \\ Bing Zhang \\ Jichun Zhang \\ Dehu Tian}

Department of Hand Surgery, The Third Hospital of Hebei Medical University, Shijiazhuang, People's Republic of China

*These authors contributed equally to this work
Correspondence: Dehu Tian Department of Hand Surgery, The Third Hospital of Hebei Medical University, I 39 Ziqiang Road, Shijiazhuang 05005 I, Hebei, People's Republic of China

Tel +86 I50 32II I 276

$\mathrm{Fax}+863$ II 88602007

Email tiandhhand@qq.com
Background: In the treatment of cubital tunnel syndrome (CuTS), in situ ulnar nerve decompression is commonly used. This study aims to investigate predictive factors for poor recovery and ulnar nerve instability following this procedure.

Methods: We enrolled 235 patients who underwent in situ ulnar nerve decompression for the treatment of CuTS from January 2010 to December 2014. All patients underwent $>2$ years' follow-up. The primary outcome was postoperative recovery, which was assessed by Messina's criteria, and the secondary outcome was postoperative ulnar nerve instability. Potential risk factors were collected from demographic data and electrodiagnostic test, which included age, gender, body mass index, history of tobacco or alcohol use, history of major medical comorbidities, disease duration, preoperative severity, motor conduction velocity, and sensory conduction velocity.

Results: A total of 208 patients (88.5\%) had satisfactory outcomes, while the other 27 patients $(11.5 \%)$ had not. There were 25 patients $(10.6 \%)$ showing postoperative ulnar nerve instability during follow-up. The multivariate analysis showed that only severe preoperative symptom (odds ratio [OR], 3.06; 95\% confidence interval [CI], 2.16-4.32) was associated with unsatisfactory postoperative outcomes in patients with $\mathrm{CuTS}(P<0.001)$. In the model investigating independent factors associated with postoperative ulnar nerve instability, we found that young age (OR, 2.41; 95\% CI, 1.63-3.58) was associated with the incidence of postoperative ulnar nerve instability $(P<0.001)$.

Conclusion: We found that severe preoperative symptom was associated with unsatisfactory postoperative outcomes, and young age was a risk factor for the incidence of postoperative ulnar nerve instability. Patients with these risk factors should be informed of the possibility of worse surgical outcomes.

Keywords: predictors, cubital tunnel syndrome, ulnar nerve decompression, multivariate analysis

\section{Introduction}

Following carpal tunnel syndrome, cubital tunnel syndrome (CuTS) is the second most frequent peripheral compressive neuropathy in the upper extremities. ${ }^{1,2}$ The clinical progression of CuTS not only affects the quality of life but can also lead to substantial morbidity. This disorder was first described by Feindel and Stratford in the year 1958. ${ }^{3}$ After that, it was gradually considered that CuTS can be categorized into idiopathic form and symptomatic form. Multiple mechanisms can lead to the development of CuTS, but it is usually considered to result from a combination of compression, traction, and friction effects. ${ }^{4}$

Conservative treatment is firstly recommended to CuTS patients with mild symptoms, and if conservative treatment fails, operative treatment is indicated..$^{5}$ There are 
three main surgical procedures for CuTS patients, including in situ decompression, medial epicondylectomy, and intramuscular, submuscular, or subcutaneous anterior transposition of the ulnar nerve, but which one is the optimal procedure remains controversial. ${ }^{6-8}$ Among these procedures, anterior transposition of the ulnar nerve is commonly used by many surgeons. This procedure can diminish dynamic ulnar nerve compression that occurs with elbow flexion by the means of transposing the ulnar nerve anterior to the medial epicondyle. Nevertheless, extensive dissection is required during the process of transposing the ulnar nerve, which may damage the vascularity of the nerve. In consideration of this situation, simple in situ decompression of the ulnar nerve, which seems to achieve similar postoperative results to transposition of the ulnar nerve, has gained popularity gradually. 5,9

The prognostic factors for postoperative outcomes of CuTS have been studied and reported previously. Various predictors, such as age, preoperative severity, and electrodiagnostic testing results, have been considered to contribute to the poor prognosis in previous studies. ${ }^{10-14}$ However, among these studies, few performed a multivariate analysis to analyze the data. Besides, most of these studies included only small samples, which may cause concern for detecting reliable outcomes. Furthermore, ulnar nerve instability is a common postoperative complication following CuTS surgery. Though predictive factors for preoperative ulnar nerve instability have been analyzed, ${ }^{15}$ there are few studies investigating factors associated with postoperative ulnar nerve instability. Thus, we conducted this retrospective study to investigate independent predictive factors for poor recovery and ulnar nerve instability after in situ decompression of ulnar nerve.

\section{Methods}

\section{Study population}

From our surgical database, we retrospectively enrolled 235 adult patients who underwent in situ ulnar nerve decompression for the treatment of CuTS from January 2010 to December 2014. The symptoms and signs of CuTS included numbness or paresthesia in the ulnar nerve distribution, weakness of pinch or grip, and positive Tinel sign at the cubital tunnel. The diagnosis of CuTS was also confirmed by electrodiagnostic tests. ${ }^{16}$ All patients underwent $>3$ months of conservative treatment, such as restrictions of repetitive elbow flexion and vitamin B12 supplementation. Those patients who showed no improvement in symptoms and signs after conservative treatment were candidates for in situ ulnar nerve decompression. Only patients who were followed up for $>2$ years were included in our study. We excluded patients with previous elbow trauma, rheumatoid arthritis, cervical radiculopathy, or inflammatory disease. Patients were also excluded if they had any reasons requiring ulnar transposition, such as severe elbow arthritis, elbow fracture or deformity, and ulnar nerve instability. This study was approved by the Regional Ethics Committee of the Third Hospital of Hebei Medical University. All the clinical data were collected after acquisition of written informed consent from the patients.

\section{Surgical technique}

Standard in situ decompression of the ulnar nerve was performed. In brief, the patient was placed in a supine position, and the shoulder was abducted to $90^{\circ}$ with external rotation. A longitudinal incision was made between the olecranon and the medial epicondyle. After separating the subcutaneous tissues, the ulnar nerve was located. Blunt or sharp dissection was carried out to release all potential sources of structural nerve compression. After that, the stability was tested by moving the elbow through the full range of motion, and it was considered to be stable if the nerve remained within the cubital tunnel throughout elbow flexion. After that, the incision was closed, and a soft dressing and an elastic bandage were used. Early flexion and extension of the elbow without supination or pronation of the forearm were encouraged.

\section{Assessment of outcomes}

All patients were assessed at least 2 years after the surgery. The primary outcome was postoperative recovery, which was assessed by Messina's criteria. ${ }^{17}$ According to the criteria, the outcomes were categorized into excellent, good, fair, and poor (Table 1). We treated it as a binary variable and defined it as satisfactory when the outcome was better than or equal to fair, and as unsatisfactory when the outcome was poor. The secondary outcome was postoperative ulnar nerve instability,

Table I Details of Messina's criteria

\begin{tabular}{ll}
\hline Messina's criteria \\
\hline Excellent & $\begin{array}{l}\text { Complete resolution of symptoms with no postoperative } \\
\text { motor or sensory deficit }\end{array}$ \\
Good & $\begin{array}{l}\text { General resolution of symptoms but occasional tenderness } \\
\text { at the incision site, mild residual decreased sensibility, or } \\
\text { residual motor weakness }\end{array}$ \\
Fair & $\begin{array}{l}\text { Improvement after surgery but with persistent sensory } \\
\text { changes, residual motor loss, muscle wasting, or persistent } \\
\text { claw deformity }\end{array}$ \\
Poor & $\begin{array}{l}\text { No improvement after the surgical procedure or worsening } \\
\text { of symptoms }\end{array}$ \\
\hline
\end{tabular}


which was defined as anterior dislocation of the nerve out of the ulnar groove and over the medial epicondyle with elbow flexion. The assessment of outcomes was completed by two independent reviewers who were blinded to the patients' information. Disagreements between the reviewers were settled by discussion, and if no consensus could be reached, a third reviewer made the final decision.

\section{Data collection}

Demographic data were collected from the medical record of each patient, including age, gender, body mass index (BMI), history of tobacco use and alcohol use, history of major medical comorbidities (hypertension and diabetes mellitus), disease duration, and preoperative severity. Medical comorbidities were defined as a history of treatment for these conditions or by findings during the preoperative assessment. Preoperative severity was assessed by McGowan's classification score. ${ }^{18}$ Patients with lesions that were characterized by paralysis of one or more of the ulnar intrinsic muscles were considered as severe. From the preoperative electrodiagnostic test, motor conduction velocity (MCV) and sensory conduction velocity (SCV) were retrieved. To perform a multivariate analysis, continuous covariates were dichotomized. There is no generally accepted cutoff point for defining young age, high BMI, or long disease duration in patients with CuTS. The choice for their particular cutoff values (age $\leq 40$ years, $>40$ years; $\mathrm{BMI} \geq 25 \mathrm{~kg} / \mathrm{m}^{2},<25 \mathrm{~kg} / \mathrm{m}^{2}$; disease duration $\geq 12$ months, $<12$ months) was based on previous literatures, clinical meaning, or the population distribution.

\section{Statistical analysis}

Continuous variables were presented as means with standard deviations, and categorical variables were presented as frequencies. The Mann-Whitney $U$ test was used for numerical data, and Fisher's exact probability test was used to identify differences in frequency of nominal variables. Variables that were found to be potentially predictive of the outcome variable from the univariate analyses $(P<0.10)$ were included in the multivariate logistic regression models. Statistical analysis was performed with the Statistical Package for Social Sciences software (version 17.0; SPSS Inc., Chicago, IL, USA), and a $P$-value of $<0.05$ was considered statistically significant.

\section{Results}

Of the 235 patients who were appropriate for in situ ulnar nerve decompression, 154 (65.5\%) were male and the other $81(34.5 \%)$ were female. The mean age of these patients was $53.3 \pm 10.9$ years. The mean disease duration was

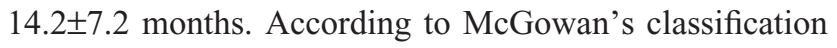
score, the number of patients with Grade 1, 2, and 3 preoperative severity was seven (3.0\%), $66(28.1 \%)$, and $162(68.9 \%)$, respectively. After $>2$ years' follow-up, the number of patients with excellent, good, fair, and poor recovery was 42 (17.9\%), 109 (46.4\%), 57 (24.3\%), and $27(11.5 \%)$, respectively. A total of 208 patients $(88.5 \%)$ had satisfactory outcomes, while the other 27 patients $(11.5 \%)$ had not. There were 25 patients (10.6\%) showing postoperative ulnar nerve instability during follow-up. Of the 27 patients in the unsatisfactory group, five (18.5\%) had postoperative ulnar nerve instability, while 20 of the 208 patients $(9.6 \%)$ in the satisfactory group had postoperative ulnar nerve instability, but the difference between the two groups was not statistically significant $(P=0.180)$.

The details of comparison between groups are shown in Table 2. There were significant differences in preoperative symptoms $(P=0.004)$, disease duration $(P=0.029)$, MCV $(P=0.023)$, and $\operatorname{SCV}(P=0.021)$. However, there was no significant difference in age, gender, BMI, history of tobacco use or alcohol use, hypertension, or diabetes mellitus $(P>0.10)$.

Table 2 A comparison of variables in patients with satisfactory and unsatisfactory outcomes

\begin{tabular}{|c|c|c|c|}
\hline Variable & $\begin{array}{l}\text { Unsatisfactory } \\
\text { group }(n=27)\end{array}$ & $\begin{array}{l}\text { Satisfactory } \\
\text { group }(n=208)\end{array}$ & $P$-value \\
\hline Age (years) & $54.1 \pm 11.3$ & $53.2 \pm 10.6$ & $0.68 I$ \\
\hline \multicolumn{3}{|l|}{ Gender } & 0.830 \\
\hline Male & 17 & 137 & \\
\hline Female & 10 & 71 & \\
\hline BMI $\left(\mathrm{kg} / \mathrm{m}^{2}\right)$ & $24.1 \pm 3.1$ & $23.5 \pm 2.7$ & 0.287 \\
\hline \multicolumn{3}{|l|}{ Tobacco use } & 0.649 \\
\hline Yes & 6 & 59 & \\
\hline No & 21 & 149 & \\
\hline \multicolumn{3}{|l|}{ Alcohol use } & 0.614 \\
\hline Yes & 4 & 42 & \\
\hline No & 23 & 166 & \\
\hline \multicolumn{3}{|l|}{ Hypertension } & 0.438 \\
\hline Yes & 7 & 39 & \\
\hline No & 20 & 169 & \\
\hline \multicolumn{3}{|l|}{ Diabetes mellitus } & 0.748 \\
\hline Yes & 2 & 23 & \\
\hline No & 25 & 185 & \\
\hline $\begin{array}{l}\text { Disease duration } \\
\text { (months) }\end{array}$ & $17.1 \pm 6.7$ & $13.8 \pm 7.4$ & 0.029 \\
\hline \multicolumn{3}{|c|}{ Preoperative severity } & 0.004 \\
\hline Severe & 25 & 137 & \\
\hline Not severe & 2 & 71 & \\
\hline$M C V(\mathrm{~m} / \mathrm{s})$ & $28.2 \pm 10.5$ & $34.1 \pm 12.8$ & 0.023 \\
\hline $\mathrm{SCV}(\mathrm{m} / \mathrm{s})$ & $23.4 \pm 11.7$ & $27.6 \pm 8.4$ & 0.021 \\
\hline
\end{tabular}

Abbreviations: BMI, body mass index; MCV, motor conduction velocity; SCV, sensory conduction velocity. 
Table 3 Multivariate logistic regression analysis of risk factors for poor recovery

\begin{tabular}{llll}
\hline Variable & OR & $\mathbf{9 5 \% ~ C l}$ & $P$-value \\
\hline Disease duration $\geq 12$ months & 2.14 & $0.75-6.16$ & 0.156 \\
Severe preoperative symptom & 3.06 & $2.16-4.32$ & $<0.001$ \\
$\mathrm{MCV}(\mathrm{m} / \mathrm{s})$ & 1.22 & $0.87-1.72$ & 0.248 \\
$\mathrm{SCV}(\mathrm{m} / \mathrm{s})$ & 1.04 & $0.68-1.58$ & 0.863 \\
\hline
\end{tabular}

Abbreviations: $\mathrm{OR}$, odds ratio; $\mathrm{Cl}$, confidence interval; $\mathrm{MCV}$, motor conduction velocity; SCV, sensory conduction velocity.

A multivariate analysis was also performed to investigate the impact of independent variables on the postoperative outcomes. The final results showed that only the severe preoperative symptom (odds ratio [OR], 3.06; 95\% confidence interval $[\mathrm{CI}], 2.16-4.32)$ was associated with unsatisfactory postoperative outcomes in patients with CuTS $(P<0.001$, Table 3). In the model investigating independent factors associated with postoperative ulnar nerve instability, we found that young age $(\mathrm{OR}, 2.41 ; 95 \% \mathrm{CI}, 1.63-3.58)$ was associated with the incidence of postoperative ulnar nerve instability. The details of results are shown in Table 4.

\section{Discussion}

Simple decompression as an initial surgical option is considered to be cost-effective for CuTS. ${ }^{9}$ Although it is well known that the number of cubital tunnel decompressions performed each year is on the rise, there remains much debate regarding independent predictive factors for postoperative outcomes and complications. In the current study, we found that $88.5 \%$ of patients had satisfactory outcomes while the other $11.5 \%$ had not. There were 25 patients showing postoperative ulnar nerve instability during $>2$ years' follow-up. The final results of the multivariate logistic analysis showed that only the severe preoperative symptom was associated with unsatisfactory postoperative outcomes in patients with CuTS, and young age was the only factor associated with the incidence of postoperative ulnar nerve instability.

The prevalence of CuTS is $1 \%$ in general population and can rise up to $7 \%$ in the working population, especially having a need for holding a tool in position. ${ }^{19,20}$ The incidence also increases with being overweight and repetitive work,

Table 4 Multivariate logistic regression analysis of risk factors for postoperative ulnar nerve instability

\begin{tabular}{llll}
\hline Variable & OR & $\mathbf{9 5 \%} \mathbf{C l}$ & $\boldsymbol{P}$-value \\
\hline Age $\leq 40$ years & $2.4 \mathrm{I}$ & $1.63-3.58$ & $<0.00 \mathrm{I}$ \\
Male gender & $\mathrm{I} .93$ & $0.62-5.97$ & 0.25 \\
$\mathrm{BMI} \geq 25 \mathrm{~kg} / \mathrm{m}^{2}$ & $\mathrm{I} .19$ & $0.67-2.08$ & 0.56 \\
\hline
\end{tabular}

Abbreviations: $\mathrm{OR}$, odds ratio; $\mathrm{Cl}$, confidence interval; $\mathrm{BMI}$, body mass index. and males are more frequently affected..$^{2,21}$ The most common position of nerve compression is the humeroulnar arcade, which partly covers the retrocondylar groove and reduces the volume of the tunnel when flexing the elbow, resulting in an increased pressure onto the ulnar nerve..$^{22}$ Principally, three operative techniques can be offered: in situ decompression of the ulnar nerve, transposition of the ulnar nerve, and medial epicondylectomy. A range of comparative studies have been conducted, showing the effectiveness of all three techniques, but eventually none has been proved to be superior. ${ }^{6-8}$ In the current study, most patients achieved satisfactory outcome during follow-up after in situ decompression of the ulnar nerve. As a simple procedure, in situ decompression of the nerve is performed most commonly in our hospital.

In the bivariate analysis, we found that preoperative severity was associated with a higher risk of poor recovery, and this result was confirmed in the multivariate analysis. To date, a number of studies have been published on prognostic factors of CuTS following in situ decompression (Table 5)..$^{10-14}$ In the year 2006, Yamamoto et al conducted a retrospective study involving 107 patients and concluded that age, duration of disease, preoperative severity, and motor nerve conduction velocity were factors associated with poor outcomes, ${ }^{14}$ while in the study by Kang et al in 2016, older age, worse preoperative grip strength, and worse two-point discrimination were demonstrated to be prognostic factors. ${ }^{12}$ Though other factors have been reported as risk factors by previous studies, our data did not detect these factors as predictive factors for postoperative outcome. We assumed that one reason for the conflicting results is that different pre- and postoperative evaluation systems have been used for determining the severity of CuTS. Another reason is likely the inclusion of patients undergoing concomitant procedures, such as fracture internal fixation, ligament reconstruction, and arthroplasty, and the various treatments used to decompress the ulnar nerve (eg, in situ decompression, anterior transposition of ulnar nerve, medial epicondylectomy). However, our study included only patients undergoing simple in situ ulnar nerve release at the cubital tunnel.

The ulnar nerve may become unstable upon decompression of the cubital tunnel in patients who did not display instability before surgery, but it was difficult even for experienced clinicians to assess the stability of the ulnar nerve on physical examination. ${ }^{23}$ We could not find any measurable parameter that reliably predicted ulnar nerve instability and need for transposition. In our multivariate analysis, the strongest predictor of instability resulting after surgery was young age. This result was in line with the study by Matzon et al, 
Table 5 Summary of previous reports on risk factors for poor surgical outcomes following ulnar nerve decompression

\begin{tabular}{|c|c|c|c|c|c|}
\hline Study & Year & Study design & $\begin{array}{l}\text { No of } \\
\text { patients }\end{array}$ & Surgical strategy & Identified risk factors \\
\hline Yamamoto et al ${ }^{14}$ & 2006 & Retrospective & 107 & $\begin{array}{l}\text { Simple decompression, anterior } \\
\text { transposition }\end{array}$ & $\begin{array}{l}\text { Age, duration of disease, preoperative } \\
\text { severity, and motor nerve conduction velocity }\end{array}$ \\
\hline Krogue et al ${ }^{13}$ & 2015 & Retrospective & 231 & Simple decompression & Prior elbow fracture \\
\hline Kang et $\mathrm{al}^{12}$ & 2016 & Prospective & 41 & $\begin{array}{l}\text { Simple decompression, anterior } \\
\text { transposition }\end{array}$ & $\begin{array}{l}\text { Older age, worse preoperative grip strength, } \\
\text { and worse two-point discrimination }\end{array}$ \\
\hline Bruder et al'" & 2017 & Retrospective & 42 & $\begin{array}{l}\text { Simple decompression, anterior } \\
\text { transposition }\end{array}$ & Duration of disease \\
\hline Suzuki et al ${ }^{10}$ & 2017 & Retrospective & 125 & $\begin{array}{l}\text { Simple decompression, anterior } \\
\text { transposition, medial epicondylectomy }\end{array}$ & Preoperative severity \\
\hline
\end{tabular}

and they assumed that young patients tend to have greater degrees of instability because more robust soft tissues and a larger triceps muscle may push the nerve out of the groove. ${ }^{15}$ Based on our data, for patients who are not diagnosed as being unstable before surgery, particularly those who are $<40$ years old, we counsel the possibility that they may show postoperative ulnar nerve instability during follow-up.

Strengths of this study include the relatively large sample size and the absence of significant heterogenicity among patients. However, there are several limitations in our study. First of all, the retrospective design and potential for bias are the typical restrictions of our study. In future, prospective studies are still needed to confirm our results. Second, all surgeries were performed independently by two surgeons. Though surgical procedures were standardized, it may be a factor that leads to different surgical outcomes. Third, only a limited number of factors were analyzed; the inclusion of other factors may provide more valuable information to us. For example, the anatomical configuration of the cubital tunnel may also play an important part in the development of postoperative ulnar nerve instability, and further studies could be performed in this aspect. Finally, though the proportion of patients with postoperative ulnar nerve instability in the unsatisfactory group was higher than that in the satisfactory group, a statistical significance was not shown in the current study. Further studies with larger sample sizes are still needed to investigate the relationship between ulnar nerve instability and unsatisfactory outcome.

In summary, the current study revealed the postoperative outcomes after ulnar nerve decompression for CuTS, and reported the incidence of postoperative ulnar nerve instability during $>2$ years' follow-up. The final results of multivariate logistic analysis showed that only the severe preoperative symptom was associated with unsatisfactory postoperative outcomes, and young age was associated with the incidence of postoperative ulnar nerve instability.

\section{Disclosure}

The authors report no conflict of interest in this work.

\section{References}

1. Chung KC. Treatment of ulnar nerve compression at the elbow. J Hand Surg Am. 2008;33:1625-1627.

2. Assmus H, Antoniadis G, Bischoff C, et al. Cubital tunnel syndromea review and management guidelines. Cent Eur Neurosurg. 2011; 72:90-98.

3. Feindel W, Stratford J. The role of the cubital tunnel in tardy ulnar palsy. Can J Surg. 1958;1:287-300.

4. Boone S, Gelberman RH, Calfee RP. The management of cubital tunnel syndrome. J Hand Surg Am. 2015;40:1897-1904.

5. Adkinson JM, Zhong L, Aliu O, Chung KC. Surgical treatment of cubital tunnel syndrome: trends and the influence of patient and surgeon characteristics. J Hand Surg Am. 2015;40:1824-1831.

6. Macadam SA, Gandhi R, Bezuhly M, Lefaivre KA. Simple decompression versus anterior subcutaneous and submuscular transposition of the ulnar nerve for cubital tunnel syndrome: a meta-analysis. J Hand Surg Am. 2008;33:1311-1314.

7. Zlowodzki M, Chan S, Bhandari M, Kalliainen L, Schubert W. Anterior transposition compared with simple decompression for treatment of cubital tunnel syndrome. A meta-analysis of randomized, controlled trials. J Bone Joint Surg Am. 2007;89:2591-2598.

8. Nabhan A, Ahlhelm F, Kelm J, et al. Simple decompression or subcutaneous anterior transposition of the ulnar nerve for cubital tunnel syndrome. J Hand Surg Br. 2005;30:521-524.

9. Song JW, Chung KC, Prosser LA. Treatment of ulnar neuropathy at the elbow: cost-utility analysis. J Hand Surg Am. 2012;37:1617-1629.

10. Suzuki T, Iwamoto T, Shizu K, et al. Predictors of postoperative outcomes of cubital tunnel syndrome treatments using multiple logistic regression analysis. J Orthop Sci. 2017;22:453-456.

11. Bruder M, Dutzmann S, Rekkab N, et al. Muscular atrophy in severe cases of cubital tunnel syndrome: prognostic factors and outcome after surgical treatment. Acta Neurochir (Wien). 2017;159:537-542.

12. Kang HJ, Oh WT, Koh IH, Kim S, Choi YR. Factors influencing outcomes after ulnar nerve stability-based surgery for cubital tunnel syndrome: a prospective cohort study. Yonsei Med J. 2016;57:455-460.

13. Krogue JD, Aleem AW, Osei DA, Goldfarb CA, Calfee RP. Predictors of surgical revision after in situ decompression of the ulnar nerve. J Shoulder Elbow Surg. 2015;24:634-639.

14. Yamamoto K, Shishido T, Masaoka T, Katori Y, Tanaka S. Postoperative clinical results in cubital tunnel syndrome. Orthopedics. 2006;29: 347-353.

15. Matzon JL, Lutsky KF, Hoffler CE, et al. Risk factors for ulnar nerve instability resulting in transposition in patients with cubital tunnel syndrome. J Hand Surg Am. 2016;41:180-183.

16. Novak CB, Lee GW, Mackinnon SE, Lay L. Provocative testing for cubital tunnel syndrome. J Hand Surg Am. 1994;19:817-820. 
17. Messina A, Messina JC. Transposition of the ulnar nerve and its vascular bundle for the entrapment syndrome at the elbow. J Hand Surg Br. 1995;20:638-648.

18. McGowan AJ. The results of transposition of the ulnar nerve for traumatic ulnar neuritis. J Bone Joint Surg Br. 1950;32-B:293-301.

19. van Rijn RM, Huisstede BM, Koes BW, Burdorf A. Associations between work-related factors and specific disorders at the elbow: a systematic literature review. Rheumatology (Oxford). 2009;48:528-536.

20. Wojewnik B, Bindra R. Cubital tunnel syndrome - review of current literature on causes, diagnosis and treatment. J Hand Microsurg. 2009; $1: 76-81$.
21. Descatha A, Leclerc A, Chastang JF, Roquelaure Y. Incidence of ulnar nerve entrapment at the elbow in repetitive work. Scand J Work Environ Health. 2004;30:234-240.

22. Iba K, Wada T, Aoki M, et al. Intraoperative measurement of pressure adjacent to the ulnar nerve in patients with cubital tunnel syndrome. J Hand Surg Am. 2006;31:553-558.

23. Murata K, Omokawa S, Shimizu T, et al. Risk factors for dislocation of the ulnar nerve after simple decompression for cubital tunnel syndrome. Hand Surg. 2014;19:13-18.

\section{Publish your work in this journal}

Therapeutics and Clinical Risk Management is an international, peerreviewed journal of clinical therapeutics and risk management, focusing on concise rapid reporting of clinical studies in all therapeutic areas, outcomes, safety, and programs for the effective, safe, and sustained use of medicines. This journal is indexed on PubMed Central, CAS,
EMBase, Scopus and the Elsevier Bibliographic databases. The manuscript management system is completely online and includes a very quick and fair peer-review system, which is all easy to use. Visit http://www.dovepress.com/testimonials.php to read real quotes from published authors.

Submit your manuscript here: http://www.dovepress.com/therapeutics-and-clinical-risk-management-journal 